\begin{tabular}{|l|l|}
\hline Postprint Version & 1.0 \\
\hline Journal website & http://vb23.bsl.nl/frontend/index.asp?custom_product_id=0168- \\
& 9428\&product_id=\{A9EE6675-58B1-4251-BD27-6FA916BB35DD \\
\hline Pubmed link & \\
\hline DOI & \\
\hline
\end{tabular}

This is a NIVEL certified Post Print, more info at http://www.nivel.eu

\title{
Multimorbiditeit in de huisartsenpraktijk
}

\author{
PROF.DR. F.G. SCHELLEVIS*
}

* Huisarts; hoogleraar Multimorbiditeit in de huisartsenpraktijk, Afdeling Huisartsgeneeskunde/EMGO+ Instituut VUmc, Amsterdam; onderzoeker, NIVEL (Nederlands Instituut voor Onderzoek van de Gezondheidszorg), Utrecht.

\begin{abstract}
SAMENVATTING
Patiënten met multimorbiditeit (die meerdere chronische ziekten tegelijk hebben) stellen de huisarts voor verschillende uitdagingen. Medisch gezien bemoeilijkt multimorbiditeit de diagnostiek van nieuwe klachten of symptomen, treden er vaak problemen op door tegenstrijdige medicamenteuze en niet-medicamenteuze behandelingen, en kan het moeilijk zijn het beloop van de afzonderlijke chronische ziekten te beïnvloeden. In organisatorische zin staat de huisarts garant voor de continuïteit van de zorg en kunnen patiënten met multimorbiditeit een beroep doen op de huisarts om de coördinatie van de zorg over te nemen. De inzet van een praktijkondersteuner en het gebruik van een zorgplan kunnen de huisarts daarbij ondersteunen.
\end{abstract}

\section{INLEIDING}

De prevalentie van de meeste chronische ziekten neemt toe met de leeftijd. Naarmate iemand ouder wordt, neemt de kans toe dat hij aan een chronische ziekte lijdt. Logischerwijs neemt met het ouder worden ook de kans toe dat iemand aan meer dan één chronische ziekte lijdt. Door het toenemend aantal ouderen in de bevolking zijn er dus ook steeds meer mensen die aan meerdere chronische ziekten lijden. Dit brengt specifieke problemen met zich mee bij de diagnostiek, behandeling en monitoring van chronische ziekten in de huisartsenpraktijk, en bij de organisatie van de zorg voor deze patiënten. Na een korte toelichting van enkele begrippen zullen deze problemen achtereenvolgens in deze bijdrage aan bod komen.

\section{BEGRIPPEN}

De termen 'comorbiditeit' en 'multimorbiditeit' zijn beide in gebruik voor het fenomeen dat iemand aan meer dan één (chronische) ziekte lijdt. De term 'comorbiditeit' werd voor het eerst gebruikt in 1967, door de Amerikaanse internist en klinisch epidemioloog Alvan Feinstein. 1 Hij definieerde comorbiditeit enkele jaren later als volgt:

'Any distinct additional clinical entity that has existed or may occur during the clinical course of a patient who has the index disease under study'. 2

Feinsteins eerste observaties gingen over de beïnvloeding van de prognose van het mammacarcinoom door het gelijktijdig bestaan van andere chronische ziekten. De term 'multimorbiditeit' dateert uit 1996 en werd toen gedefinieerd als:

'The co-occurrence of multiple chronic or acute diseases and medical conditions within one person'. 3

Deze twee definities hebben gemeen dat het gaat om patiënten met meer dan één ziekte. Maar ze verschillen in het gezichtspunt van waaruit gekeken wordt. Bij comorbiditeit gaat het om een patiënt met een zogeheten indexziekte, bijvoorbeeld een mammacarcinoom of diabetes mellitus, die daarnaast een andere - comorbide - ziekte heeft. Bij multimorbiditeit gaat het om de verdeling van het aantal ziekten in een populatie: er zijn mensen zonder ziekten, met één ziekte en met meer dan één ziekte. Bij 
multimorbiditeit is er dus geen sprake van een indexziekte maar zijn alle ziekten als het ware gelijk. De termen 'comorbiditeit' en 'multimorbiditeit' worden meestal gereserveerd voor combinaties van chronische ziekten. Ik gebruik in deze bijdrage de term 'multimorbiditeit', uit het voorgaande moge duidelijk zijn dat deze ook comorbiditeit omvat.

De prevalentie van multimorbiditeit is niet eenduidig vast te stellen. Deze is onder andere afhankelijk van het aantal en de aard van de ziekten die meetellen, de setting waarin multimorbiditeit wordt gemeten (algemene bevolking, huisartsenpraktijk, ziekenhuis, verzorgings- of verpleeghuis) en de leeftijd. 4 Onder aanname van een aantal condities is in de algemene bevolking 56-72\% van de 55-plussers bekend met twee of meer chronische ziekten. Onder 55-plussers in de huisartsenpraktijk worden vergelijkbare prevalenties gevonden (56-66\%). 4,5 Duidelijk is dat multimorbiditeit bij ouderen eerder regel dan uitzondering is.

Multimorbiditeit heeft belangrijke consequenties voor de volksgezondheid en de gezondheidszorg. Op basis van een systematisch literatuuronderzoek blijkt multimorbiditeit samen te hangen met een grotere kans op sterfte, met een verminderd lichamelijk en geestelijk functioneren en met een minder goede kwaliteit van leven. Het spreekt vanzelf dat multimorbiditeit ook een extra druk legt op de zorgvoorzieningen en leidt tot een toename van de kosten daarvan. 6,7

\section{MULTIMORBIDITEIT IN DE HUISARTSENPRAKTIJK}

Voor het optimale huisartsgeneeskundig handelen kan steeds meer teruggegrepen worden op protocollen en richtlijnen, zoals de standaarden van het Nederlands Huisartsen Genootschap (NHG). Hierin is de bestaande wetenschappelijke kennis samengevat, en waar deze ontbreekt aangevuld met op consensus gebaseerde richtlijnen van experts. Veel van deze kennis is echter gebaseerd op wetenschappelijk onderzoek onder patiëntenpopulaties die niet representatief zijn voor de patiënten in de huisartsenpraktijk. Om methodologische redenen worden oudere patiënten en/of patiënten met multimorbiditeit meestal uitgesloten van deelname aan wetenschappelijk onderzoek. Dit heeft tot gevolg dat de bestaande evidencebased richtlijnen zich meestal beperken tot één ziekte en nauwelijks aandacht besteden aan tegelijkertijd optredende andere chronische ziekten. Deze richtlijnen zijn dus niet zonder meer toepasbaar bij patiënten met multimorbiditeit. Uiteraard vraagt dit om een herbezinning van wetenschappers bij het stellen van onderzoeksprioriteiten en om de ontwikkeling van innoverende onderzoeksmethoden, maar ondertussen wordt van (huis)artsen verwacht dat ze ook aan patiënten met multimorbiditeit kwalitatief goede zorg verlenen. Hieronder volgen daarom een aantal aandachtspunten, gebaseerd op common sense, die van belang zijn bij de diagnostiek, behandeling en monitoring van chronische ziekten bij patiënten met multimorbiditeit.

\section{DiAGNOSTIEK}

Wanneer een patiënt zich presenteert met een nieuwe klacht zal de huisarts trachten door middel van anamnese, lichamelijk onderzoek en eventueel aanvullend onderzoek een diagnose te stellen. Is de patiënt al bij de huisarts bekend met een of meer chronische ziekten, dan is het zaak om die ziekte(n) ook in de diagnostische overwegingen te betrekken. Hoe meer chronische ziekten, hoe complexer deze afweging is. De nieuw gepresenteerde klacht kan weliswaar een uiting zijn van een nieuw probleem, maar ook van een reeds bekende chronische ziekte, of een bijwerking zijn van de behandeling van een van die ziekten.

Mijnheer Van A. is 63 jaar. Drie maanden geleden kreeg hij een acuut myocardinfarct waarvoor hij korte tijd in het ziekenhuis opgenomen werd. De hartfunctie is goed hersteld en is nu stabiel, mede dankzij de geneesmiddelen die hij gebruikt, waaronder een bètablokker. Mijnheer Van A. komt, drie maanden na het infarct, op het spreekuur met klachten van moeheid, slecht slapen en een verminderd concentratievermogen.

Deze eenvoudige casus laat de dilemma's duidelijk zien. Zijn de klachten te wijten aan het doorgemaakte myocardinfarct of zijn het bijwerkingen van de bètablokker? Of zijn ze een aanwijzing voor een beginnende depressie? Uit onderzoek is bijvoorbeeld bekend dat huisartsen bij patiënten die al bekend zijn met een chronische ziekte terughoudender zijn in het stellen van de diagnose depressie dan bij patiënten zonder een chronische ziekte. 8

Het diagnostisch handelen bij patiënten met multimorbiditeit vraagt dus om extra alertheid van de huisarts: betrek bij de differentiaaldiagnose uitdrukkelijk ook de (behandeling en het beloop van de) reeds bekende chronische ziekten. 


\section{BEHANDELING}

Zowel de medicamenteuze als de niet-medicamenteuze behandelingen van de chronische ziekten bij patiënten met multimorbiditeit kunnen problemen geven.

Veel patiënten met multimorbiditeit krijgen een medicamenteuze behandeling die kan worden omschreven als polyfarmacie (het langdurig gebruik van vijf of meer geneesmiddelen tegelijkertijd). Bij polyfarmacie moet men niet alleen bedacht zijn op interacties tussen geneesmiddelen, maar ook aandacht hebben voor de haalbaarheid van het geneesmiddelenregime (dosering, aantal giften per dag), voor overbehandeling en zelfs voor onderbehandeling (meestal vanuit een goedbedoelde terughoudendheid om nog meer geneesmiddelen voor te schrijven, hoewel deze wel geïndiceerd zijn).

Maar ook niet-medicamenteuze adviezen voor meerdere, tegelijkertijd bij eenzelfde patiënt voorkomende chronische ziekten kunnen tegenstrijdigheden opleveren.

Boyd et al. hebben de evidence-based richtlijnen voor de behandeling van een hypothetische 79-jarige patiënte met multimorbiditeit (osteoporose, artrose, diabetes mellitus, hypertensie en chronisch obstructief longlijden) eens naast elkaar gezet. 9 Het regime voor deze patiënte zou bestaan uit:

- twaalf verschillende geneesmiddelen, in te nemen in negentien doses op vijf verschillende tijdstippen van de dag;

- veertien verschillende en deels tegenstrijdige niet-medicamenteuze adviezen en leefregels, waaronder bewegen en gedoseerde rust, spieroefeningen, goed schoeisel en vermijden van prikkels die benauwdheid kunnen veroorzaken;

- voedingsadviezen: beperkte energie-inname en beperkt gebruik van natrium, kalium, vet, cholesterol, magnesium, calcium en alcohol.

Het moge duidelijk zijn dat hier een taak ligt voor de huisarts voor het leveren van 'maatwerk' bij de toepassing van richtlijnen voor de optimale behandeling. 10

\section{MONITORING}

Het beloop van chronische ziekten varieert per ziekte en per patiënt. Zo wordt het beloop van chronisch obstructief longlijden meestal gekenmerkt door een geleidelijke verslechtering van de longfunctie, met tijdelijke exacerbaties. Het beloop van diabetes mellitus varieert per patiënt en wordt sterk bepaald door het optreden van complicaties als hart- en vaatziekten, retinopathie, neuropathie of nefropathie. Bij patiënten met multimorbiditeit kan het beloop van de ene ziekte het beloop van de andere ziekte beïnvloeden, en het is niet altijd duidelijk welke ziekte waarvoor verantwoordelijk is. Dit kan het de huisarts moeilijk maken om in te grijpen in het beloop van een ziekte. Naarmate de patiënt ouder en/of de medische zorg complexer wordt, zal de behandeling van ziekten en beïnvloeding van het beloop steeds meer plaats maken voor het behoud van het lichamelijk, psychisch en sociaal functioneren. Dit geldt des te meer indien de medische zorg voor de verschillende chronische ziekten tegenstrijdige eisen stelt en er keuzes moeten worden gemaakt die consequenties hebben voor het beloop.

\section{DE ORGANISATIE VAN DE ZORG VOOR PATIËNTEN MET MULTIMORBIDITEIT}

Met uitzondering van enkele generalisten zoals de huisarts, de verpleeghuisarts, de kinderarts en de klinisch geriater, is de medische zorg orgaanspecifiek georganiseerd. Dit geldt met name in de poliklinische en klinische setting, maar ook in de eerstelijns en de transmurale zorg is er een toenemende neiging tot ziektespecifieke organisatie van de zorg; de diabetesketenzorg is daarvan een goed voorbeeld. Bij deze orgaan- of ziektespecifieke zorg wordt nauwelijks of geen rekening gehouden met patiënten met multimorbiditeit. In aanvulling op de ziektespecifieke zorg is voor patiënten met multimorbiditeit continuïteit en coördinatie van zorg van groot belang. 7

\section{CONTINUÏTEIT VAN ZORG}

Van oudsher heeft de huisarts de verantwoordelijkheid opgeëist voor de continuïteit van de zorg; dit is de kern van de huisartsgeneeskunde. In het recente NHG-Standpunt Huisartsenzorg voor ouderen wordt dit nog eens bevestigd, juist waar het ouderen met complexe problemen betreft. 11 Concreet betekent dit dat de huisarts verantwoordelijkheid neemt voor het - zo nodig - coördineren van de deelname van patiënten met multimorbiditeit aan meerdere ziektespecifieke zorgprogramma's, en met name de coördinatie op zich neemt van de diagnostische en therapeutische activiteiten die daaruit voortvloeien. Het kan daarbij zowel 
gaan om organisatorische aspecten (bijvoorbeeld het op elkaar afstemmen van afspraken met medisch specialisten) als om inhoudelijke aspecten (bijvoorbeeld medicatiebewaking).

Specifieke aandacht is nodig voor de continuïteit van informatie. 12 Veelal beschikt de huisarts over het meest complete medische dossier van de patiënt. Dit betekent dat de huisarts het meest complete overzicht heeft, maar het maakt de huisarts ook verantwoordelijk voor het voldoende en adequaat informeren van alle bij de patiënt betrokken zorgverleners. Het toekomstige elektronisch patiëntendossier maakt deze rol van de huisarts niet overbodig.

\section{COÖRDINATIE VAN ZORG}

Naarmate patiënten aan meer chronische ziekten lijden, neemt het aantal hulpverleners dat bij de zorg voor de patiënt betrokken is toe. $13 \mathrm{Zo}$ is de kans om binnen een jaar in een ziekenhuis te worden opgenomen voor een diabetespatiënt met drie andere chronische ziekten tienmaal zo groot als voor een diabetespatiënt zonder multimorbiditeit. 14 Patiënten met multimorbiditeit geven zelf aan dat het verbeteren van de coördinatie tussen zorgverleners voor hen een belangrijke prioriteit is. 7 In veel gevallen zijn de patiënt of diens primaire verzorgers goed in staat deze coördinatie zelf op zich te nemen. Maar wanneer zij, bijvoorbeeld door het toenemend aantal betrokken hulpverleners, het overzicht dreigen te verliezen, ligt het voor de hand dat de huisarts de rol van case manager op zich neemt. De belangrijkste taak is het realiseren van een eenduidig beleid ten aanzien van de zorg van verschillende zorgverleners, zodat eenieder, inclusief de patiënt, duidelijkheid heeft over zijn rol. Het moge duidelijk zijn dat dit vraagt om een proactieve opstelling van de huisarts. Overigens zal het in werkelijkheid vaker de praktijkondersteuner (POH) of praktijkverpleegkundige zijn die de rol van case manager op zich neemt, onder supervisie van de huisarts. Voor de invulling van case management is een zorgplan een bruikbaar instrument. Aan het opstellen van een zorgplan gaat een systematische inventarisatie van de problemen vooraf. Het zorgplan omvat de te bereiken doelen, de activiteiten die daarvoor nodig zijn, en de termijn waarop de doelen gerealiseerd worden.

\section{HET PERSPECTIEF VAN DE PATIËNT MET MULTIMORBIDITEIT}

In de voorgaande paragrafen werden de problemen waarmee multimorbiditeit gepaard gaat belicht vanuit het perspectief van de huisarts. In aanvulling daarop is het zinvol om multimorbiditeit vanuit het perspectief van de patiënt te bekijken.

\section{ERVARINGSDESKUNDIGHEID}

Wat geldt voor zeldzame ziektebeelden geldt ook voor multimorbiditeit: er is in de literatuur weinig informatie beschikbaar over de invloed die combinaties van ziekten hebben op het leven en de beleving van patiënten. Daarom is de eigen ervaringsdeskundigheid van patiënten met multimorbiditeit van groot belang. Het is dan ook nuttig om de patiënt te laten vertellen over zijn ervaringen met de ziekten waaraan hij lijdt, de gevolgen daarvan en de behandelingen. Deze kennis kan behulpzaam zijn bij het interpreteren van klachten en symptomen, en ook bij het inschatten van de haalbaarheid van behandelingen.

\section{BESLUITVORMING OVER BEHANDELING}

Bij patiënten met multimorbiditeit is de keuze voor een behandeling vaak niet eenduidig. Een keuze voor een behandeling van de ene ziekte kan negatieve gevolgen hebben voor een andere ziekte. Het voorschrijven van een nieuw geneesmiddel kan weliswaar de klachten doen verminderen, maar vergroot de kans op bijwerkingen. Het gaat in de meeste gevallen om chronische ziekten waarbij genezing niet aan de orde is, hooguit de beïnvloeding van het beloop van de ziekten. De keuze voor een behandeling moet dan ook gebaseerd worden op een afweging van prioriteiten. Wat vindt de patiënt het belangrijkste? Een geneesmiddel gaan gebruiken dat een vermindering van de klachten geeft maar de kans op complicaties doet toenemen? Het is de taak van de huisarts om de patiënt voldoende informatie te geven om vervolgens in een gezamenlijk gesprek een goede afweging te kunnen maken. Juist in het geval van patiënten met multimorbiditeit kan dat lastig zijn. Het is belangrijk om daarbij te checken of de patiënt het goed begrepen heeft. Een deel van de patiënten met multimorbiditeit zal moeite hebben om alle informatie in zich op te nemen, of zelfs wilsonbekwaam zijn. In dat geval is zorgvuldig overleg met de mantelzorgers aangewezen. 


\section{TOT SLOT}

Patiënten met multimorbiditeit zullen een steeds groter deel van de patiëntenpopulatie in de huisartsenpraktijk gaan uitmaken. Zij stellen de huisarts voor verschillende uitdagingen, zowel medischinhoudelijk als op het terrein van praktijkorganisatie en coördinatie van de zorg. Met ondersteuning binnen de praktijk en adequate tweedelijns geriatrische zorg moet de huisarts deze uitdagingen met vertrouwen kunnen aangaan. 15 De patiënten met multimorbiditeit zullen de huisarts er dankbaar voor zijn.

\section{LITERATUUR}

1. Feinstein AR. Clinical judgment. New York: Williams \& Wilkins; 1967.

2. Feinstein AR. The pre-therapeutic classification of co-morbidity in chronic disease. J Chron Dis. 1970;23:455-68.

3. Akker M van den, Buntinx F, Knottnerus JA. Comorbidity or multimorbidity: what's in a name? A review of literature. Eur J Gen Pract. 1996;2:65-70.

4. Schram MT, Frijters D, Lisdonk EH van de, Ploemacher J, Craend AJM de, Waal MWM de, et al. Setting and registry characteristics affect the prevalence and nature of multimorbidity in the elderly. $\mathrm{J}$ Clin Epidemiol. 2008;61:1104-12.

5. Schram MT, Waal MWM de, Craen AJM de, Deeg DJH, Schellevis FG. Multimorbiditeit: De nieuwe epidemie. TSG. 2008;86:23-5.

6. Gijsen R, Hoeymans N, Schellevis FG, Ruwaard D, Satariano WA, Bos GAM van den. Causes and consequences of comorbidity: A review. J CLin Epidemiol. 2001;54:661-74.

7. Heijmans MJWM, Rijken PM, Schellevis FG, Bos GAM van den. Meer dan een ziekte: De gevolgen van comorbiditeit vanuit het perspectief van chronisch zieken en gehandicapten. Utrecht: NIVEL; 2003.

8. Nuyen J, Volkers AC, Verhaak PFM, Schellevis FG, Groenewegen PP, Bos GAM van den. Accuracy of diagnosing depression in primary care: The impact of chronic somatic and psychiatric co-morbidity. Psychol Med. 2005;35:1185-95.

9. Boyd CM, Darer J, Boult C, Fried LP, Boult L, Wu AW. Clinical practice guidelines and quality of care for older patients with multiple comorbid diseases. JAMA. 2005;94:716-24.

10. Weel C van, Schellevis FG. Comorbidity and guidelines: Conflicting interests. Lancet. 2006;367:550-1.

11. Nederlands Huisartsen Genootschap. NHG-Standpunt Toekomstvisie huisartsenzorg:

Huisartsgeneeskunde voor ouderen. Utrecht: NHG; 2007.

12. Schers H. Continuity of care in general practice [dissertation]. Nijmegen: Katholieke Universiteit; 2004.

13. Westert GP, Satariano WA, Schellevis FG, Bos GAM van den. Patterns of comorbidity and the use of health services in the Dutch population. Eur J Publ Health. 2001;11:365-72.

14. Struijs JN, Baan CA, Schellevis FG, Westert GP, Bos GAM van den. Comorbidity in patients with diabetes mellitus: Impact on medical health care utilization. BMC Health Serv Res. 2006;6:84.

15. Gezondheidsraad. Ouderdom komt met gebreken: Geneeskunde en zorg bij ouderen met multimorbiditeit. Nr. 2008/01. Den Haag: Gezondheidsraad; 2008. 